\title{
Novel Simulation Workshop Improves Performance in Vacuum Delivery
}

\author{
Katrina Calvert1*, Mathias Epee1, Anne Karzcub', Cliff Neppe', Michael Allen³, \\ Wendy Hughes ${ }^{4}$, Paul McGurgan5, Richard King', Alexander Maouris', \\ Dorota Doherty5, Panos Maouris ${ }^{1}$ \\ ${ }^{1}$ King Edward Memorial Hospital, Perth, Australia \\ 2Joondalup Health Campus, Joondalup, Australia \\ ${ }^{3}$ St John of God Hospital, Subiaco, Perth, Australia \\ ${ }^{4}$ Broome Hospital, Broome, Australia \\ ${ }^{5}$ School of Women's and Infants' Health, University of Western Australia, Crawley, Australia \\ ${ }^{6}$ Bond University, Queensland, Australia \\ Email: "katrina.calvert@health.wa.gov.au
}

Received 26 February 2016; accepted 20 June 2016; published 23 June 2016

Copyright (C) 2016 by authors and Scientific Research Publishing Inc.

This work is licensed under the Creative Commons Attribution International License (CC BY). http://creativecommons.org/licenses/by/4.0/

(c) (i) Open Access

\section{Abstract}

Background: Operative vaginal delivery is a common obstetric intervention, with the potential to cause harm to mother and baby. Training in operative delivery traditionally comprised junior trainees learning the skills under supervision, then practicing and refining them independently. Recently this model has come under scrutiny, with the advent of simulation-based training suggesting a method by which the skills of safe delivery may be taught without risk. Multiple training courses exist, but few have been subjected to evaluation. Aims: The primary aim was to investigate if a simulation-based training workshop, where the development of a successful technique for vacuum delivery occurs using a collaborative, problem-solving approach, improves the rate of correct vacuum cup placement. The secondary aim was to determine if the workshop leads to improvement in theoretical knowledge of vacuum delivery. Methods: Participants on three workshops were assessed for their performance in vacuum delivery prior to and following a multimodal training program. Participants included general practitioner obstetricians, obstetric trainees and resident medical officers. Evaluation occurred using a standardised Likert-scaled rating sheet and utilising a diagrammatic representation of cup placement. Results: The participants demonstrated significant improvement (median post-pre score $1, p<0.001$ ) in the accuracy of cup placement, in a variety of practical core skills and in theoretical knowledge of vacuum delivery. Discussion: Participation in a simulation-based vacuum delivery workshop improves the performance of obstetric trainees and GP obstetricians. Further work is required to evaluate the performance of such training modalities on clinically relevant outcomes.

"Corresponding author. 
Keywords

Vacuum Delivery, Simulation, Training, Patient Safety

\section{Introduction}

Operative vaginal delivery is a core skill for obstetricians and General Practitioner obstetricians (GP obstetricians). The rate of vacuum delivery in Australia is $8 \%$ [1], which is similar to rates in the UK, France and the United States [2]-[4]. Operative vaginal delivery may be undertaken for fetal indications such as fetal distress, or for maternal indications such as failure to progress or maternal exhaustion [2] [4]. Although a commonplace intervention, vacuum delivery is not without complications. Consequences for the baby can include minor trauma such as cephalhaematoma in up to $13.6 \%$ [5] [6] in addition to potentially fatal trauma such as subgaleal haemorrhage in up to $21 \%$ of vacuum deliveries [6], with inaccurate placement of the cup being a significant contributor to the more severe cases [5] [7]. Vacuum delivery also carries a risk of maternal trauma [2], particularly in cases where the vacuum fails to deliver the baby and either a second instrument is required, or a caesarean delivery results. There is a wide variation between reported failure rates depending on the fetal head position, the choice of cup and the skill of the accoucheur [8] [9]. Failure rates differ with different types of cup used [2] but even using the same cup (Kiwi Omnicup) failure rates vary from 2\% to 34\% [3] [7] [10]. It is widely accepted that the key to minimising failure rates and fetal trauma is accurate cup placement over the flexion point [4] [10] [11]. Correct cup placement (flexing \& median) is particularly important in malpositions, when the fetal head faces in a direction other than occipito-anterior [11] [12]. Unfavourable cup applications (deflexing or paramedian) are the commonest cause of failed vacuum delivery, accounting for $40 \%$ of failed vacuum deliveries [13]. Not only do trainee obstetricians find correct cup placement a challenge, but they may also fail to recognise when cup placement has been suboptimal. In a 2004 study from the UK, obstetricians recorded their perception of where the vacuum cup had been placed during a vacuum delivery on one form while on a second form a pediatrician indicated the actual site of the cup placement as observed on the baby [13]. The vacuum cup was considered to have been sub optimally sited in $40 \%$ of all failed ventouse deliveries. In all but one of these cases the operators felt that they had applied the cup in an appropriate position. This failure of insight is likely to be associated with poor learning and a low likelihood of subsequent skill development and improvement in outcomes.

The senior author, (PM), has developed a simplified problem-based teaching method of vacuum cup placement, which is easy to teach in a short workshop using mannequins [14].

The primary aim of this study was to investigate if the instrumental delivery workshop improved the rate of correct vacuum cup placement in junior medical staff. We also wanted to determine if the workshop led to improvement in theoretical knowledge of vacuum delivery.

\section{Materials and Methods}

The study was conducted during three vaginal delivery workshops held in Broome and Perth, Western Australia between July 2014 and September 2015. Workshop participants included pre-vocational trainees, specialist obstetric trainees and general practitioner obstetricians from hospitals around Western Australia. The study sample was self-selected as junior doctors volunteered to participate in the workshops, and all workshop participants consented to participate in the workshop and the study.

The demographics of the workshop participants are shown in Table 1.

Ethical approval was prospectively granted by the Women's and Children's Health Service Governance, Evidence, Knowledge and Outcomes (GEKO) Committee (\#GEKO6505).

The workshop included theoretical and practical components. At the start of the workshop, participants were asked to answer a questionnaire. Following this they were asked to perform a set of vacuum deliveries using the Lucy TM pelvic model and fetal head. The head was placed in three different positions and each delivery was assessed using a standardised proforma, recording the positioning of the cup, the manoeuvres used during the delivery, and the overall impression of the assessor. In addition, a visual representation of the delivery was made using a diagram of the fetal head, with the position of the cup recorded on the diagram, and measurements taken from the edges of the cup to the bony landmarks on the model (see Figure 1). 
Table 1. Demographic data of workshop participants.

\begin{tabular}{cccc}
\hline Variable & & Number & $\%$ \\
\hline \multirow{2}{*}{ Gender } & Male & 8 & 22.2 \\
& Female & 28 & 77.8 \\
\hline \multirow{2}{*}{ Background } & Junior trainee & 21 & 58.3 \\
& Senior trainee & 3 & 8.3 \\
Estimated number of & GP obstetrician & 12 & 33.3 \\
previous vacuum & 0 & 4 & 11.1 \\
deliveries & $1-10$ & 15 & 41.7 \\
& $10-30$ & 7 & 19.4 \\
\hline
\end{tabular}

The study participants were then provided with an open-ended discussion revising the basic concepts and safety aspects of vacuum delivery using audio visual aids. Particular emphasis was placed on the importance of correct cup placement on the flexion point. This was followed by a 30 minute interactive workshop using the Lucy TM and modified Lucy’s head TM mannequins. The workshop participants were invited to work out the steps required to achieve correct cup placement on the fetal head for each of the three different positions as previously discussed. The group were thus able to collaboratively develop a simple unified technique which helps to achieve correct cup placement in all of the possible fetal head positions.

Following the workshop, each participant was observed doing the same set of vacuum deliveries a second time, and scored by the same assessor, in order to rule out inter-observer variability as a confounding factor. In this way a set of paired observations (pre and post education) were created for each workshop participant. The participants also completed the same questionnaire at the conclusion of the workshop in order to ascertain whether an improvement in knowledge could be demonstrated. Each workshop was completed in 90 minutes.

All assessments for the practical skills were performed using a simple four-level Likert scale between 0 (worst) and 3 (best). Training was provided to all assessors prior to the first workshop, in order to standardise the use of the Likert scales. As the same assessor observed each participant pre and post, and as the results were analysed as post-pre scores, any inter-observer variability in the use of the Likert scales will have been irrelevant to the final data analysis. The actual number of correct answers in the theoretical questionnaire generated a score out of 10 questions.

Performances pre- and post-workshop were summarised for each skill and overall using medians, interquartile ranges (Q1 - Q3) and ranges. Categorical data were summarised using frequency distributions. Assessment of change in performance was performed using paired post-and pre-workshop scores analysed using the Wilcox on Signed Rank test for paired data. SPSS statistical software was used for data analysis (IMB SPSS Statistics for Windows, Version 20.0. Armonk., NY: IBM Corp.). All hypothesis tests were two-sided and p-values $<0.05$ were considered statistically significant.

\section{Results}

Workshop data were collected on 36 workshop participants; 21 junior trainees (58.3\%), 3 senior trainees (8.3\%) and 12 GP obstetricians (33.3\%). Analysis as to the impact of training on specific groups of participants was not performed due to the small numbers of senior trainees and GP obstetricians.

Pre-, post-scores and post-pre score differences are shown in Table 2.

Significant improvements were seen in the primary criterion of cup placement accuracy as well in almost all of the secondary criteria evaluated, with the exception of episiotomy timing, where the small number of participants with paired data recorded precluded any valid conclusions regarding the timing of episiotomy.

There was also an improvement in theoretical knowledge in all 36 participants with a demonstrated increase in the questionnaire score from a median of 5 (interquartile range 3 - 5.8, range 2 - 7) before the workshop to a median of 7 (interquartile range $7-8$, range $6-10)$ at the end of the workshop $(p<0.001)$. The median increase in the score was 3 (interquartile range 2 - 4, range 1 - 6).

\section{Discussion}

The demonstration of improvement in clinical outcomes following simulation based training is an essential endeavour and a challenging one [15]. The assumption is frequently made that training using mannequins will improve delivery skills, translating into improved outcomes for mothers and babies [16]. Evidence for this improve- 


\section{Vacuum lnitial Test $\quad$ Name}

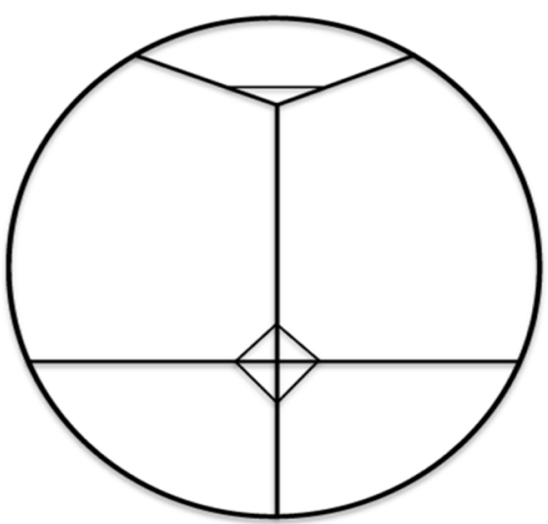

OA Position:

Distance from edge of posterior fontanelle

Distance from edge of anterior fontanelle

Right cup edge to sagittal suture

Left cup edge to sagittal suture

Position at delivery

\section{OT Position}

Distance from edge of posterior fontanelle $\quad \mathrm{cm}$

Distance from edge of anterior fontanelle $\quad \mathrm{cm}$

Right cup edge to sagittal suture $\quad \mathrm{cm}$

Left cup edge to sagittal suture

Position at delivery

\section{OP Position:}

Distance from edge of posterior fontanelle $\quad \mathrm{cm}$

Distance from edge of anterior fontanelle $\quad \mathrm{cm}$

Right cup edge to sagittal suture $\quad \mathrm{cm}$

Left cup edge to sagittal suture

$\mathrm{cm}$

Position at delivery

\section{Figure 1. Pictorial assessment tool used to record exact cup placement during training.}

ment remains elusive, and there are several reasons why that may be the case. Demonstration of a clear impact of education would ideally take place under circumstances where the population was standardised in terms of prior experience, where a simple evaluation tool was available, and where the population could be evaluated, educated, and evaluated again a second time, without the corruption of external training modalities or clinical experience diluting the effect of the training. Clearly in obstetrics this is not possible. Training occurs in an ad hoc way during clinical interactions, with the educational value of the experience taking a distant second place to the clinical considerations for mother and child. Clinical outcomes of great consequence, such as severe trauma or perinatal death, are thankfully rare, requiring large studies to demonstrate any measurable impact of training. Using simulation as a proxy to assess clinical skills could be argued to be a suboptimal level of evaluation, as an improvement in simulation skills may not necessarily translate into an improvement in clinical skills. 
Table 2. Post-pre training score results for each item. Data shown using medians and interquartile ranges (Q1 - Q3).

\begin{tabular}{|c|c|c|c|c|c|c|c|}
\hline \multirow{2}{*}{ Item } & \multicolumn{2}{|l|}{ Pre-scores } & \multicolumn{2}{|l|}{ Post-scores } & \multicolumn{2}{|l|}{ Post-pre scores } & \multirow{2}{*}{$\mathrm{p}$ value } \\
\hline & Med (Q1 - Q3) & $\mathrm{N}$ & Med (Q1 - Q3) & $\mathrm{N}$ & Med (Q1 - Q3) & $\mathrm{N}$ & \\
\hline \multicolumn{8}{|l|}{ Practical skills* } \\
\hline $\begin{array}{l}\text { Cup insertion } \\
\text { technique }\end{array}$ & $1(1-2)$ & 36 & $2(2-3)$ & 36 & $1(1-2)$ & 36 & $\mathrm{p}<0.001$ \\
\hline $\begin{array}{l}\text { Cup application } \\
\text { position }\end{array}$ & $1(1-2)$ & 36 & $2(2-3)$ & 36 & $1(1-2)$ & 36 & $\mathrm{p}<0.001$ \\
\hline $\begin{array}{l}\text { Distance to } \\
\text { perineum }\end{array}$ & $1(0-2)$ & 25 & $2(2-3)$ & 29 & $1(0.8-2)$ & 22 & $\mathrm{p}=0.001$ \\
\hline $\begin{array}{l}\text { Initial axis of } \\
\text { traction }\end{array}$ & $1(0-2)$ & 36 & $3(2-3)$ & 35 & $2(1-3)$ & 35 & $\mathrm{p}<0.001$ \\
\hline $\begin{array}{l}\text { Position of } \\
\text { accoucher }\end{array}$ & $0(0-2)$ & 36 & $3(3-3)$ & 36 & $2(1-2)$ & 36 & $\mathrm{p}<0.001$ \\
\hline $\begin{array}{l}\text { Timing of } \\
\text { upward pull }\end{array}$ & $1(1-2)$ & 34 & $3(2-3)$ & 36 & $2(0-2)$ & 34 & $\mathrm{p}<0.001$ \\
\hline $\begin{array}{l}\text { Episiotomy } \\
\text { timing }\end{array}$ & $1(0-2)$ & 11 & $2(1.3-3)$ & 16 & $0(0-1.5)$ & 9 & $\mathrm{p}=0.197$ \\
\hline $\begin{array}{l}\text { Overall } \\
\text { impression }\end{array}$ & $1(1-2)$ & 36 & $2(2-3)$ & 36 & $1(1-2)$ & 36 & $\mathrm{p}<0.001$ \\
\hline $\begin{array}{l}\text { Theoretical } \\
\text { skills }\end{array}$ & $5(3-5.8)$ & 36 & $7(7-8)$ & 36 & $3(2-4)$ & 36 & $\mathrm{p}<0.001$ \\
\hline
\end{tabular}

* Pre- and post-scores range between 0 and 3, and post-pre scores between -1 and 3 with score of 0 representing no change and positive scores indicating improvement. ${ }^{* *}$ Max pre- and post-scores total score is 10 . P-values obtained using Wilcoxon signed ranks test.

However, the obstetric community has previously embraced simulation-based outcomes as applicable in the clinical setting [17] and is likely to continue to do so regarding instrumental delivery training.

This workshop was successful in its primary aim of demonstrating a significant improvement in the rate of correct vacuum cup placement. As previous clinical studies have shown [3] [7]-[9], this is expected to lead to an improvement in clinical outcomes by decreasing vacuum delivery failure rates, especially in mal positions. In each of the three workshops the participants independently developed the same technique for cup insertion. Use of the Lucy TM models allowed the workshop participants to observe the effect of placing the cup straight into the vagina without considering fetal head position, in comparison to placing the cup correctly. Due to maternal pelvic anatomy, the correct position for a vacuum cup is achieved by placing the cup posteriorly in the vagina, with decreasing emphasis on the degree of posterior placement as the baby rotates to an occipito-anterior position. As the workshop participants were able to see this effect for themselves during the practical session, they were able to derive the correct technique independently, leading to active learning, and an improvement in performance. It is this learner-derived aspect of correct technique development which differentiates this workshop from other similar interventions, and which is likely to result in improved retention of knowledge in the long term.

The secondary aim of demonstration of an improvement in theoretical knowledge was also achieved (see Table 2). Further work is required to see whether this improvement is sustained over time in the clinical setting.

This study demonstrates that a short, low-cost intervention of an instrumental delivery training workshop can lead to an improvement in a variety of core clinical skills, including overall technique and theoretical knowledge. Further research in this area is required to demonstrate whether such skills are incorporated into routine clinical practice and retained over time, and whether a clinical benefit of training on maternal or paediatric outcomes can be demonstrated.

\section{Acknowledgements}

The authors would like to thank the participants in the operative delivery workshops for their involvement in this project. The authors have no competing interests to declare. 


\section{References}

[1] Royal Australian College of Obstetricians and Gynaecologists. Instrumental Vaginal Delivery (C-Obs 16) (2012) RANZCOG College Statement 2012. www.ranzcog.edu.au/college-statements-guidelines.html

[2] Equy, V., David-Tchouda, S., Dreyfus, M., et al. (2015) Clinical Impact of the Disposable Ventouse iCup versus a Metallic Vacuum Cup: A Multicenter Randomized Controlled Trial. BMC Pregnancy and Childbirth, 15, 332. http://dx.doi.org/10.1186/s12884-015-0771-1

[3] Attilakos, G., Sibanda, T., Winter, C., Johnson, N. and Draycott, T. (2005) A Randomised Controlled Trial of a New Handheld Vacuum Extraction Device. British Journal of Obstetrics and Gynaecology, 112, 1510-1515. http://dx.doi.org/10.1111/j.1471-0528.2005.00729.x

[4] Yeomans, E. (2010) Operative Vaginal Delivery. Obstetrics \& Gynecology, 115, 645-653. http://dx.doi.org/10.1097/AOG.0b013e3181cfbefd

[5] Doumouchtsis, S. and Arulumaran, S. (2006) Head Injuries after Instrumental Vaginal Deliveries. Current Opinion in Obstetrics and Gynaecology, 18, 129-134. http://dx.doi.org/10.1097/01.gco.0000192983.76976.68

[6] Royal Australian College of Obstetricians and Gynaecologists (2015) Prevention Detection and Management of Subgaleal Haemorrhage in the Newborn (C Obs 28). RANZCOG College Statement 2015. www.ranzcog.edu.au/college-statements-guidelines.html

[7] Baskett, T., Fanning, C. and Young, D. (2008) A Prospective Observational Study of 1000 Vacuum Assisted Deliveries with the OmniCup Device. Journal of Obstetrics and Gynaecology Canada, 30, 573-580. http://dx.doi.org/10.1016/S1701-2163(16)32890-0

[8] Al-Kadri, H., Sabr, Y., Al-Saif, S., Abdulaimoun, B., Ba’Aqeel, H. and Salah, A. (2003) Failed Individual and Sequential Instrumental Vaginal Delivery: Contributing Risk Factors and Maternal-Neonatal Complications. Acta Obstetricia et Gynecologica Scandinavica, 82, 642-648. http://dx.doi.org/10.1034/j.1600-0412.2003.00162.x

[9] Cheong, Y., Abdullahi, H., Lashen, H. and Fairlie, F. (2004) Can Formal Education and Training Improve the Outcome of Instrumental Delivery? European Journal of Obstetrics \& Gynecology and Reproductive Biology, 113, 139144. http://dx.doi.org/10.1016/S0301-2115(03)00340-3

[10] Vacca, A. (2001) Operative Vaginal Delivery: Clinical Appraisal of a New Vacuum Extraction Device. Australian and New Zealand Journal of Obstetrics and Gynaecology, 41, 156-160. http://dx.doi.org/10.1111/j.1479-828X.2001.tb01200.x

[11] Bird, G. (1976) The Importance of Flexion in Vacuum Extractor Delivery. British Journal of Obstetrics and Gynaecology, 83, 194-200. http://dx.doi.org/10.1111/j.1471-0528.1976.tb00808.x

[12] Vacca, A. (2003) Handbook of Vacuum Delivery in Obstetric Practice. Vacca Research, Brisbane.

[13] Sau, A., Sau, M., Ahmed, H. and Brown, R. (2004) Vacuum Extraction: Is There Any Need to Improve the Current Training in the UK? Acta Obstetricia et Gynecologica, 83, 466-470. http://dx.doi.org/10.1111/j.0001-6349.2004.0399.x

[14] Maouris, P., Jennings, B., Ford, J., et al. (2010) Outreach Obstetrics Training in Western Australia Improves Neonatal Outcome and Decreases Caesarean Sections. Journal of Obstetrics and Gynaecology, 30, 6-9. http://dx.doi.org/10.3109/01443610903276409

[15] Calvert, K., McGurgan, P., Debenham, E., Gratwick, F. and Maouris, P. (2013) Emergency Obstetric Simulation Training: How Do We Know Where We Are Going, If We Don't Know Where We Have Been? Australian and New Zealand Journal of Obstetrics and Gynaecology, 53, 509-516. http://dx.doi.org/10.1111/ajo.12120

[16] Gale, A., Siassakos, D., Attilakos, G., Winter, C. and Draycott, T. (2014) Operative Vaginal Birth: Better Training for Better Outcomes. British Journal of Obstetrics and Gynaecology, 121, 643-644. http://dx.doi.org/10.1111/1471-0528.12560

[17] Cass, G., Crofts, J. and Draycott, T. (2011) The Use of Simulation to Teach Clinical Skills in Obstetrics. Seminars in Perinatology, 35, 68-73. http://dx.doi.org/10.1053/j.semperi.2011.01.005 


\section{Submit or recommend next manuscript to SCIRP and we will provide best service for you:}

Accepting pre-submission inquiries through Email, Facebook, Linkedin, Twitter, etc A wide selection of journals (inclusive of 9 subjects, more than 200 journals)

Providing a 24-hour high-quality service

User-friendly online submission system

Fair and swift peer-review system

Efficient typesetting and proofreading procedure

Display of the result of downloads and visits, as well as the number of cited articles

Maximum dissemination of your research work

Submit your manuscript at: http://papersubmission.scirp.org/ 